\title{
THE WIDE SYNTHETIC VERSATILITY OF FIVE MEMBERED RINGS CONTAINING PHOSPHORUS
}

\author{
Vinicius Caliman
}

Departamento de Química - ICEx - UFMG - 31270-901 - Belo Horizonte - MG

Recebido em 28/4/99; aceito em 21/12/99

\begin{abstract}
The chemistry of cyclopentadiene rings has been widely studied. This review article deals with a similar chemistry of new compounds containing from 1 to 5 phosphorus atoms on the ring substituting the carbon atoms. The neutral rings containing one, two and three phosphorus atoms can be used as building blocks for the synthesis of new organic compounds containing phosphorus. These rings plus the anionic ones also show great potential as ligands in coordination chemistry. The aim of this article is to show how important this new area is and how diverse the chemistry related to a single type of ring can be.
\end{abstract}

Keywords: cyclopentadiene containing phosphorus; organophosphorus; coordination compounds.

\section{INTRODUCTION}

Five membered rings containing phosphorus atoms have been synthesized since 1959. However, nearly $75 \%$ of all known rings of this kind were prepared in the last ten years, showing the importance that chemists are giving to this type of compounds. The two areas favored with the development of these rings are organic and coordination chemistry. In a general way, we intend to give the reader a complete view of the chemistry concerning these rings, presenting the synthesis, structural data, reactivity and coordination chemistry of this important class of compounds. The work described in this review is mainly concerned with fivemembered organic ring systems containing one, two or three phosphorus atoms. These rings can be neutral (phospholes) or anionic species (phospholides). Mono- di- and triphospholes have already been reported in the literature, and their structure is presented in Figure 1 (A, $\mathbf{B}$ and $\mathbf{C}$, respectively). Phospholide anions (also called phosphacyclo-pentadienyls) containing from 1 to 5 phosphorus atoms (D-H) have also been reported.

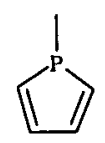

(A)
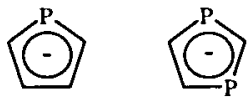

(E)<smiles>Cp1ccpc1</smiles>

(B)

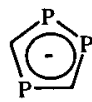

(F)<smiles>Cp1cpcp1</smiles>

(C)

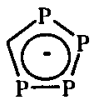

(G)

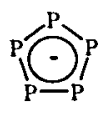

(H)
Figure 1

\section{SYNTHESIS OF PHOSPHOLES, DIPHOSPHOLES AND TRIPHOSPHOLES}

\section{Phospholes}

Phospholes of the type $\mathrm{PC}_{4} \mathrm{R}_{4} \mathrm{R}^{\prime}\left(\mathrm{R}=\mathrm{R}^{\prime}=\mathrm{Ph}(\mathbf{1})\right)$ were first described by Leavitt et al. ${ }^{1}$ in 1959 (Figure 2), who reacted the dilithium derivative 1,4-dilithio-1,2,3,4-tetraphenylbutadiene
(2) with dichlorophenylphosphine $\mathrm{PhPCl}_{2}$ to give the $1,2,3,4,5$ pentaphenylphosphole (1).

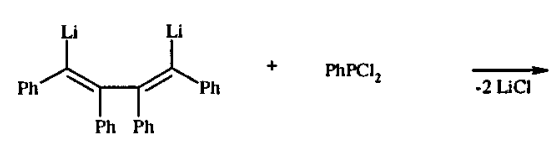

(2)<smiles></smiles>

(1)
Figure 2

Many routes to prepare phospholes have been described in the literature ${ }^{2-7}$. The simplest and most useful method was initially proposed by Mathey ${ }^{8}$ and after a few improvements ${ }^{9}$ the method was subsequently patented ${ }^{10}$. It involves a direct dehydrohalogenation by tertiary amines of 1-halophospholenium halides (3), which can be prepared by different methods $^{11-14}$ (Figure 3).

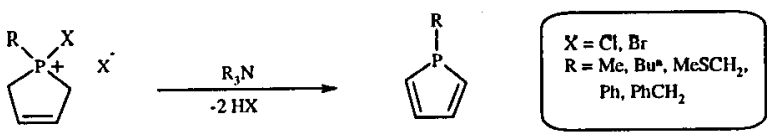

(3)

Figure 3

When $\mathrm{R}$ is phenyl, the yields are often quite high and this allowed 1-phenyl-3,4-dimethylphosphole to be produced on a $30 \mathrm{~kg}$ scale. A comprehensive review by Mathey ${ }^{15}$ includes several sections dealing with the organic chemistry of these types of ring systems, where different synthetic routes to prepare phospholes can be found.

\section{Diphospholes}

Diphospholes with general formula $\mathrm{P}_{2} \mathrm{C}_{3} \mathrm{R}_{3} \mathrm{R}^{\prime}\left(\mathrm{R}=\mathrm{H}, \mathrm{Bu}^{\mathrm{t}}, \mathrm{Ph}\right.$; $\mathrm{R}^{\prime}=\mathrm{SiMe}_{3}, \mathrm{P}_{2} \mathrm{C}_{3} \mathrm{Bu}_{3}^{\mathrm{t}}$ ) are less well-known and little data have been reported in the literature to date. Mathey and co-workers ${ }^{16}$ described the first diphosphole in 1991, via silylation of the bis(pentacarbonyl)tungsten complex anion (4) (Figure 4) to give the 1,3-diphosphole (5) containing two $\left[\mathrm{W}(\mathrm{CO})_{5}\right]$ fragments.

Later, Nixon and co-workers ${ }^{17}$ reported the synthesis of a dimeric compound $\mathrm{P}_{4} \mathrm{C}_{6} \mathrm{Bu}_{6}^{\mathrm{t}}$ (6) containing two 1,3-diphosphole 


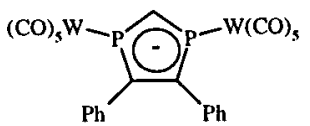

(4)

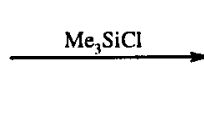

Figure 4

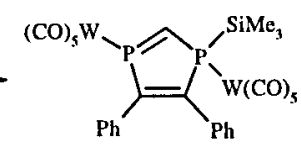

(5) units linked by a P-P bond (Figure 5). Compound (6) was obtained by oxidative coupling of two $\left(\mathrm{P}_{2} \mathrm{C}_{3} \mathrm{Bu}_{3}^{\mathrm{t}}\right)^{-}$ring anions (7) using a ruthenium complex at low temperature.

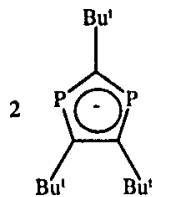

(7)

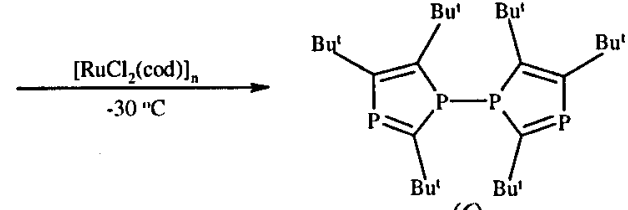

(6)
Figure 5

\section{Triphospholes}

Although triphosphole rings have been synthesized only recently, their organic and coordination chemistry was developed much faster than the chemistry related to diphosphole rings. Figure 6 shows the four possible structures (I-L) for triphosphole rings, however the only two triphospholes reported to date are of type (I).<smiles>Cp1cpcp1</smiles>

(I)<smiles>Cp1cppc1</smiles>

(J)<smiles>Cp1ccpp1</smiles>

(K)

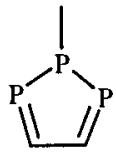

(L)
Figure 6

The triphosphole rings reported so far have been synthesized by alkylation of a triphospholide anion (Figure 7). The anion ring (8 and 9) is treated with a bulky alkyl group $\mathrm{BrCH}\left(\mathrm{SiMe}_{3}\right)_{2}$, at room temperature, to give the triphosphole. As expected, the alkylation of the 1,2,4-triphospholide anions ( 8 and 9) takes place exclusively at one of the two directly bonded phosphorus atoms due to their less sterically hindered nature. The compounds are obtained in about 50\% yield as orange crystals, and both triphospholes (10 and 11) have been fully characterized by several spectroscopic techniques and their structure determined by X-ray diffraction studies ${ }^{18,19}$. This simple and reproducible synthetic route allowed the chemistry of this ring to be studied in detail.

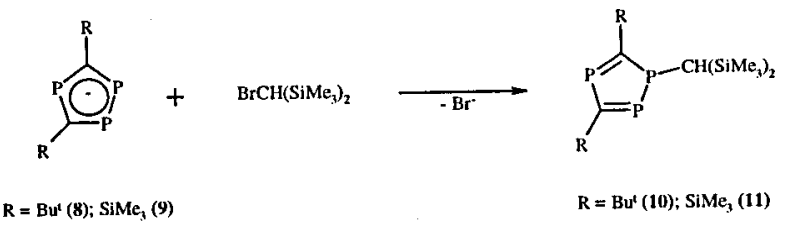

Figure 7

To the best of our knowledge there is no example of tetraand pentaphosphole. Baudler et al. ${ }^{20}$ tried without success to obtain pentaphospholes $\mathrm{P}_{5} \mathrm{R}(\mathrm{R}=\mathrm{Me}, \mathrm{Et})$ by alkylation of the
$\mathrm{P}_{5}$ anion (12) (Figure 8). It appears that the expected pentaphospholes are so unstable that they give spontaneously a mixture of polyalkylphosphanes.

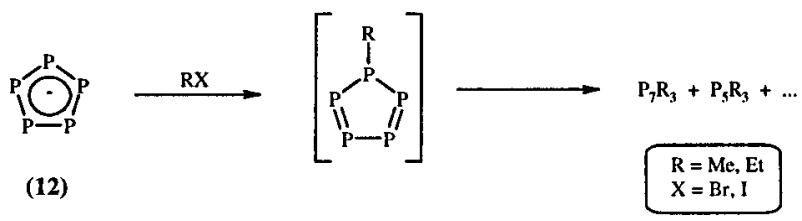

Figure 8

\section{STRUCTURAL DATA AND AROMATICITY OF PHOSPHOLES AND TRIPHOSPHOLES}

Since the synthesis of the first phosphole, the key issue concerning these heterocyclic ring systems was their potential aromaticity. It is important to mention that the concept of aromaticity is dependent upon the criteria employed to measure it, i.e. molecular structure, chemical reactivity, UV spectroscopy. Nevertheless, aromatic phospholes require a flat ring with the electron lone pair on the phosphorus atom highly delocalised.

In 1970, Egan et al. ${ }^{21,22}$ demonstrated by variable temperature NMR studies that the barrier to pyramidal inversion at phosphorus in 1-isopropyl-2-methyl-5-phenylphosphole has the extraordinarily low value of $16 \mathrm{kcal} / \mathrm{mol}$. This value is $c a .20$ $\mathrm{kcal} / \mathrm{mol}$ lower than that for saturated 5-membered cyclic phosphines, indicating $(3 p-2 p) \pi$ delocalisation and aromaticity in phosphole systems. Almost at the same time McPhail and coworkers $^{2,23}$, who reported the first X-ray molecular structure of a phosphole (Figure 9), presented a convincing argument against phosphole aromaticity. The 1-benzylphosphole (13) has a nonplanar geometry with the phosphorus and $\mathrm{C}(6)$ being displaced by $0.208 \AA$ and $1.357 \AA$ respectively, to opposite sides of the plane through $\mathrm{C}(2) \mathrm{C}(3) \mathrm{C}(4) \mathrm{C}(5)$.

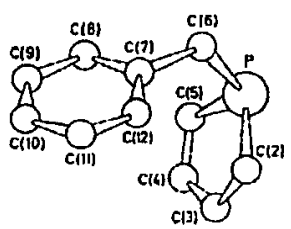

$\mathrm{P}-\mathrm{C}(2)=1.786(5), \mathrm{P} . \mathrm{C}(5)=1.780(4), \mathrm{P}-\mathrm{C}(6)=1.858(4), \mathrm{C}(2)-\mathrm{C}(3)=1.343(6), \mathrm{C}(3)-\mathrm{C}(4)=1438(6), \mathrm{C}(4)-\mathrm{C}(5)=1.343(7), \mathrm{C}(2)-\mathrm{P}-\mathrm{C}(5)=$ $90.7(2), \mathrm{C}(2)-\mathrm{P}-\mathrm{C}(6)=106.1(2), \mathrm{C}(5)-\mathrm{P}-\mathrm{C}(6)=105.9(2)$

Figure 9. X-ray molecular structure of 1-benzylphosphole (13), together with some selected bond lengths $(\AA)$ and bond angles $\left({ }^{\circ}\right)^{2}$.

The three following features suggested that phospholes are only weakly aromatic: (i) the pyramidal phosphorus atom $\left(\Sigma_{\text {angles }}=302.7^{\circ}\right)$, $(i i)$ the rather long intracyclic P-C bonds (1.780 and $1.786 \AA$ ), and (iii) the $\mathrm{C}=\mathrm{C}$ bond distances, $\mathrm{C}(2)$ $\mathrm{C}(3)$ and $\mathrm{C}(4)-\mathrm{C}(5)(1.343 \AA$, each) which lie close to the ethylene value $(1.334 \AA)^{24}$. These conclusions were supported by the results of photoelectron spectroscopic studies, using a series of phospholes (14 and 16) and phospholanes (15 and 17) (Figure 10) reported later by Mathey and co-workers ${ }^{25}$. These results showed that the electron lone pairs in phospholes (14) and (16) take no part in a cyclic five-membered ring conjugation since saturation of the cis-butadiene system in the five-membered ring has no noticeable influence on the energy of the lone pair. Accordingly, phospholes in their ground state conformations consist of localised diene systems and lone pairs of electrons at the phosphorus atoms. In this sense phospholes are not aromatic. 
<smiles></smiles>

(14)<smiles>c1ccc(P2CCCC2)cc1</smiles>

(15)<smiles>Cc1ccc(C)p1-c1ccccc1</smiles>

(16)<smiles>CC1CCC(C)P1c1ccccc1</smiles>

(17)
Figure 10

After some controversy, general agreement was reached and it is widely accepted that phospholes are only weakly aromatic. In a series of five-membered rings containing a heteroatom and a diene fragment, the following order by decreasing aromaticity was obtained, based on structural criteria ${ }^{15}$ : thiophenes $>$ pyrroles > furans > phospholes > cyclopentadienes.

In a recent article, Quinn et al. ${ }^{26,27}$ synthesized a phosphole having pronounced characteristics of aromaticity. It was reported the synthesis of a sterically crowded 1-(2,4-di-tertbutyl-6-methylphenyl)-3-methylphosphole which contains a noticeably flatter $\mathrm{P}$ atom than 1-phenylphosphole. Photoelectron spectroscopy has been explored as a tool to measure the flattening of the phosphorus pyramid in the phosphole.

When the first triphosphole was prepared in 1995, its potential aromaticity was discussed bringing back the discussion concerning the aromaticity involving five membered rings containing heteroatoms.

The chemical behavior and the molecular structure of the triphosphole ring strongly suggest a high aromatic character. Some structural data concerning mono-, di- and triphospholes are given in Table 1. The tricoordinated phosphorus atoms in this type of ring systems (attached to the - $\mathrm{R}$ group) are pyramidal in all cases $\left(\alpha+\beta+\gamma<360^{\circ}\right)$. Despite that, when going from mono- to triphospholes, there is a significant increase in the planarity of this phosphorus center $\left(\Sigma_{\text {angles }}=302.7,320.0\right.$ and $342.3^{\circ}$, respectively) which indicates that some kind of electronic delocalisation (or aromaticity) is increasing in the ring. To support the fact that the aromaticity is increasing from mono- to triphospholes, a comparison is made of the bond lengths of compounds (6) and (10), which have the same $\left(\mathrm{Bu}^{\mathrm{t}}\right)$ substituent on the carbon. The two P-C bond lengths (a and c, see Table 1) are significantly shorter in compound (10) (1.734(4) and 1.763(4) $\AA$, respectively) than in compound (6) (1.784(5) and 1.816(5) $\AA$, respectively) and the $\mathrm{P}-\mathrm{C}$ bond length (b, see Table 1$)$ is longer in compound (10) $(1.720(3) \AA)$ than in compound (6) $(1.673(5)$
$\AA$ ). These observations clearly suggest that the electronic delocalisation is much stronger in triphospholes than in monophosphole rings. For a completely delocalised diene system the $\mathrm{P}-\mathrm{C}$ bond lengths would be expected to be as equal as possible and, using the c-b (c minus b) differences as a measure of delocalisation, the triphosphole is more aromatic $(0.043 \AA)$ than the diphosphole $(0.143 \AA)$.

The 1-[bis(trimethylsilyl)methyl]-3,5-bis(trimethylsilyl)-1,2,4triphosphole (11), which was recently synthesised ${ }^{19}$, has a planar tricoordinate phosphorus atom. The molecular structure obtained for a single-crystal X-ray diffraction study (Figure 11) reveals the planarity of the five-membered 1,2,4-triphosphole ring system with a sum of angles at the tricoordinate phosphorus atom of $358.7^{\circ}$. It is noteworthy that the shortest P-C bond length, namely P1-C1 (1.684(7) A), involves the tricoordinate phosphorus atom $\mathrm{P} 1$ and is significantly shorter than $\mathrm{P} 2-\mathrm{C} 2$

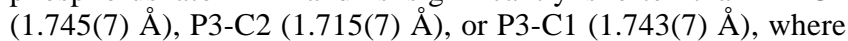
the phosphorus atoms are dicoordinate.

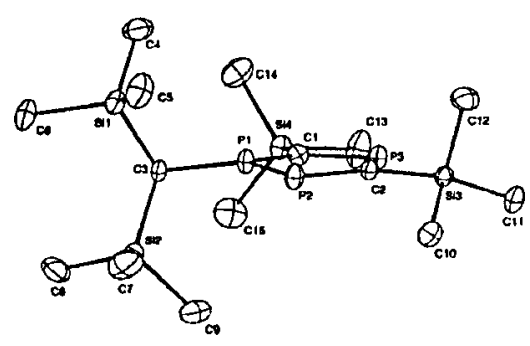

$\mathrm{P}(1)-\mathrm{C}(1)=1.684(7), \mathrm{P}(1)-\mathrm{C}(3)=1.811(6), \mathrm{P}(1)-\mathrm{P}(2)=2.056(3), \mathrm{P}(2)-\mathrm{C}(2)=1.745(7), \mathrm{P}(3)-\mathrm{C}(2)=1.715(7), \mathrm{P}(3)-\mathrm{C}(1)=1.743 ; \mathrm{C}(1)-\mathrm{P}(1)-$
$\mathrm{C}(3)=125.1(4), \mathrm{C}(1)-\mathrm{P}(1)-\mathrm{P}(2)=110.5(3), \mathrm{C}(3)-\mathrm{P}(1)-\mathrm{P}(2)=123.1(3), \mathrm{C}(2)-\mathrm{P}(2)-\mathrm{P}(1)=92.3(2), \mathrm{C}(2)-\mathrm{P}(3)-\mathrm{C}(1)=103.8(3)$.

Figure 11. X-ray molecular structure of 1-[bis(trimethylsilyl)methyl]3,5-bis(trimethylsilyl)-1,2,4-triphosphole (11), together with some selected bond lengths $(\AA)$ and bond angles $\left({ }^{\circ}\right)^{19}$.

The above structure is not only planar, but also aromatic, in agreement with previous conclusions drawn for planar phospholes from theoretical studies ${ }^{28-33}$.

\section{REACTIVITY OF MONO-, DI- AND TRIPHOSPHOLES}

\section{Phospholes}

Numerous reviews describe the chemistry of phospholes ${ }^{15,34-36}$. The objective of this account is to summarize the

Table 1: Structural data for mono-, di- and triphospholes.

\begin{tabular}{|c|c|c|c|c|}
\hline${ }_{\gamma}^{\left\langle\stackrel{\alpha}{P} \prod_{\mathrm{R}}\right.}$ & 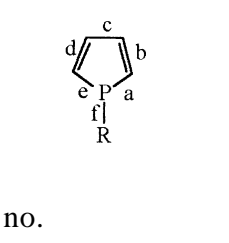 & $\begin{array}{c}\qquad \prod_{\mathrm{P}} \\
\mathrm{R} \\
\left(\mathrm{R}=\mathrm{CH}_{2} \mathrm{Ph}\right) \\
(\mathbf{1 8})^{2}\end{array}$ & $\begin{array}{l}\left.{ }_{\mathrm{R}}^{\mathrm{R}}=\mathrm{P}_{2} \mathrm{C}_{3} \mathrm{Bu}_{3}^{\mathrm{t}}\right) \\
(\mathbf{6})^{17}\end{array}$ & 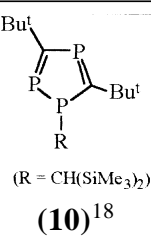 \\
\hline $\begin{array}{c}\text { Bond angles*, } \\
\text { degree. }\end{array}$ & $\begin{array}{c}\alpha \\
\beta \\
\gamma \\
\Sigma(\alpha+\beta+\gamma)\end{array}$ & $\begin{array}{c}90.7(2) \\
105.9(2) \\
106.1(2) \\
302.7\end{array}$ & $\begin{array}{c}99.7(2) \\
107.2(2) \\
113.1(2) \\
320.0\end{array}$ & $\begin{array}{l}105.8(1) \\
115.3(1) \\
121.2(2) \\
342.3\end{array}$ \\
\hline $\begin{array}{c}\text { Bond lengths*, } \\
\AA\end{array}$ & $\begin{array}{l}a \\
b \\
c \\
d \\
e \\
f\end{array}$ & $\begin{array}{l}1.786(5) \\
1.343(6) \\
1.438(6) \\
1.343(7) \\
1.780(4) \\
1.858(4)\end{array}$ & $\begin{array}{l}1.784(5) \\
1.673(5) \\
1.816(5) \\
1.397(7) \\
1.819(9) \\
2.244(2)\end{array}$ & $\begin{array}{l}1.734(4) \\
1.720(3) \\
1.763(4) \\
1.718(4) \\
2.098(1) \\
1.826(4)\end{array}$ \\
\hline
\end{tabular}

\footnotetext{
* As indicated at the top of the table.
} 
important points concerning the chemistry of this type of compound. The phosphole ring undergoes a wide variety of chemical reactions, for example both electrophilic and nucleophilic reactions occur at the phosphorus atom. DielsAlder reactions at the diene system, thermal and light induced transformations, expansion or opening of the ring framework, have also been established.

One of the most specific and synthetically useful reactions of phospholes is their cleavage by alkali metals at the exocyclic phosphorus-carbon bond ${ }^{37}$ (Figure 12). The resulting planar and highly aromatic phospholide anions readily react at the phosphorus atom in a variety of ways to afford new phospholes. This synthetic route allows the replacement of any $\mathrm{R}$ substituent at phosphorus, in phospholes, by a very wide range of other substituents.

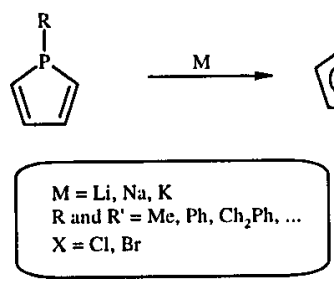

Figure 12

Another specific reaction of the phosphole ring takes place when a nucleophilic attack at the phosphorus atom is achieved by treatment with alkyllithium compounds (Figure 13). Thus, 1-phenyl-3,4-dimethylphosphole (19) easily reacts with tertbutyllithium to give 1-tert-butyl-3,4-dimethylphosphole (20) via an intermediate phosphoranyl anion $(\mathbf{2 1})^{38}$. This reaction is a good example of the enhanced reactivity of phosphorus in phospholes toward nucleophilic reagents. The corresponding reaction does not appear to work with LiMe, which is less nucleophilic than $\mathrm{LiPh}$.

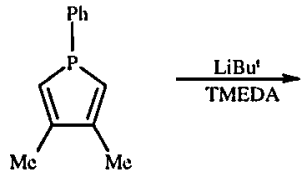

(19)

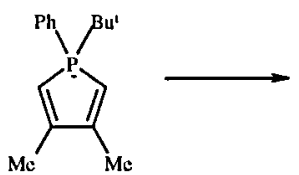

(21)

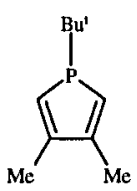

(20)
Figure 13

It has also been possible to force phospholes to undergo Diels-Alder reactions at the diene system but, as a general rule, it can be stated that the dienic system of phospholes is poorly reactive. This observation is obviously correlated with the cyclic delocalisation within the ring, which in spite of its relative weakness reduces the availability of the 4 p-electrons. Nevertheless, compound (19) cleanly reacts with N-phenylmaleimide at moderate temperatures to give the expected $[4+2]$ adduct (22) in $50 \%$ yield $^{39}$ (Figure 14 ).

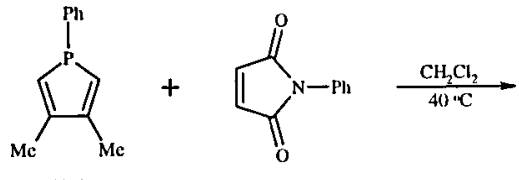

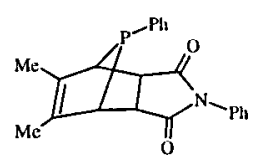

(22)
Figure 14

As expected, upon oxidation, sulphurisation, quaternisation or complexation of the phosphole lone pair, the reactivity of the dienic system sharply increases.

\section{Diphosphole}

The only reported reaction concerning the diphosphole ring (6) is the cleavage of the exocyclic phosphorus-phosphorus bond by an excess of $\mathrm{Na}$ metal in monoglyme ${ }^{17}$ (Figure 15). As the diphosphole used in this reaction is a dimer containing two $\mathrm{P}_{2} \mathrm{C}_{3} \mathrm{Bu}_{3}^{\mathrm{t}}$ units, connected by the P-P bond, the sole product from this reaction is the $\left(\mathrm{P}_{2} \mathrm{C}_{3} \mathrm{Bu}_{3}^{\mathrm{t}}\right)^{-}(7)$ anion. This route has been described as the exclusive way to a pure sample of compound (7).

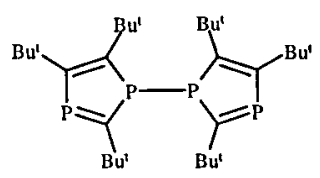

(6)

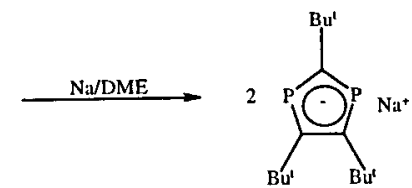

(7)
Figure 15

\section{Triphosphole}

The chemistry of triphosphole rings is just starting to develop due to its relatively recent synthesis ${ }^{18}$ and it appears to be very promising. Like phospholes, the triphospholes also suffer a nucleophilic attack when treated with alkyllithium. The reaction of 1,2,4-triphosphole (10) with alkyllithium led to addition of the alkylgroup to the $\mathrm{P}$ atom of the ring, adjacent to the $s p^{3}$ hybridized $\mathrm{P}$ to give rise to the triphosphacyclopentenyl-lithium complex $\mathrm{P}_{3} \mathrm{C}_{2} \mathrm{Bu}_{2}^{\mathrm{t}} \mathrm{CH}\left(\mathrm{SiMe}_{3}\right)_{2} \mathrm{RLi}(\mathrm{DME})\left(\mathrm{R}=\mathrm{Me}(\mathbf{2 3}), \mathrm{Bu}^{\mathrm{n}}\right.$ (24) ${ }^{40}$ (Figure 16).

This type of unsaturated ring anion system is known also for the compound $\left(\mathrm{P}_{3} \mathrm{C}_{2}\left(\mathrm{SiMe}_{3}\right)_{4}\right)$ recently described by Thelen et al. ${ }^{41}$.

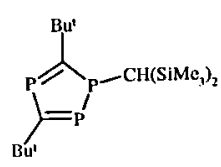

(10)
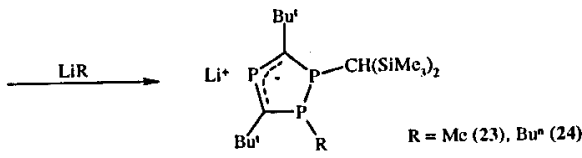

Figure 16

The triphosphole (10) also undergoes an electrocyclisation reaction when irradiated with visible light to give a triphosphabicyclo compound $(\mathbf{2 5})^{42}$ (Figure 17). This compound is highly fluxional in solution and undergoes rapid [1,3] suprafacial sigmatropic shifts of PX from PA to PB. This process is facilitated by the very weak P-P bond and by the low inversion barrier of the PX atom. Compound (25) has been characterized as a complex containing a $\left[\mathrm{W}(\mathrm{CO})_{5}\right]$ fragment (26) and by a full structurally characterized insertion product (27) formed by treatment with $\left[\mathrm{PtCl}_{2}\left(\mathrm{PEt}_{3}\right)\right]_{2}{ }^{43}$.

The last two examples about the reactivity of the triphosphole (10) deal with sulfur and selenium elements. The ring reacts with these elements in different ways. A complex reaction mixture results from the treatment of (10) with $S_{8}$ in benzene in the presence of $\mathrm{Et}_{3} \mathrm{~N}$ and the unusual pentasulfide $\mathrm{P}_{3} \mathrm{C}_{2} \mathrm{Bu}_{2}^{\mathrm{t}} \mathrm{CH}\left(\mathrm{SiMe}_{3}\right)_{2} \mathrm{~S}_{5}$ (28) (Figure 18) was isolated in $28 \%$ yield and structurally characterized by NMR, mass spectrometry and by a single crystal X-ray diffraction study.

The analogous reaction with selenium unexpectedly gave a low yield of the 1,3,5-ditertiarybutyl-1,2,4-selenadiphosphole $\mathrm{P}_{2} \mathrm{C}_{2} \mathrm{Bu}_{2}{ }_{2} \mathrm{Se}(29)$ isolated as yellow oil that was fully characterized by its ${ }^{1} \mathrm{H},{ }^{13} \mathrm{C},{ }^{31} \mathrm{P}$ and ${ }^{77} \mathrm{Se}$ NMR spectra ${ }^{40}$. 


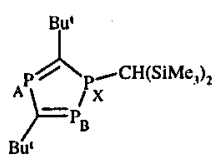

(10)
(25)

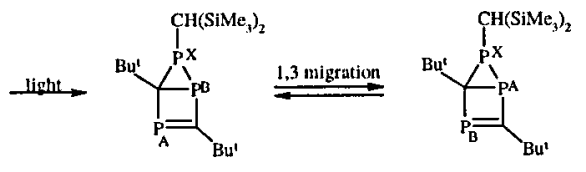

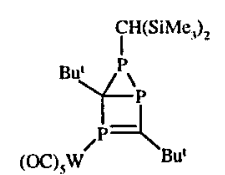

(26)
Figure 17

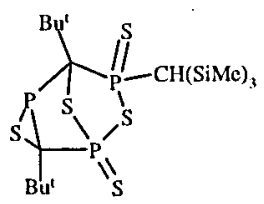

(28)
(27)

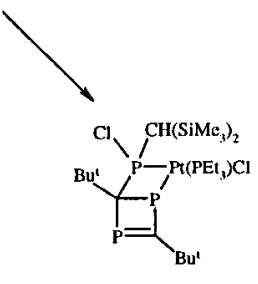<smiles></smiles>

Figure 18 complexes of formula $\left[\mathrm{PtXL}_{3}\right]^{+} \mathrm{X}^{-}(\mathrm{L}=$ phosphole ligand $)$ were also obtained when phospholes were used in excess.

Complexes containing phospholes as four electron ligands are not very common. This type of complex seems to be very unstable due to the high reactivity of the lone pair of the phosphorus atom. In order to obtain them it is necessary to deactivate the phosphorus atom by attaching electron withdrawing substituents to it and to prevent complexation through the lone pair by steric hindrance. Working with TPP (30) and $\left[\mathrm{Fe}(\mathrm{CO})_{5}\right]$, Cookson et al. $^{45}$ obtained the TPP ring $\eta^{4}$ bonded to an $\left[\mathrm{Fe}(\mathrm{CO})_{3}\right]$ fragment (32) (Figure 20).<smiles></smiles>

(30)

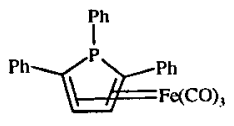

(32)
Figure 20

The first complex in which the phosphole ring acted as a sixelectron donor via the phosphorus lone pair and the dienic system was discovered by Braye et al. ${ }^{49}$. Thus, the reaction of 1,2,3,4,5pentaphenylphosphole (PPP) (1) with $\left[\mathrm{Fe}_{3}(\mathrm{CO})_{12}\right]$ affords complex (33) in 36\% yield, among other products (Figure 21).

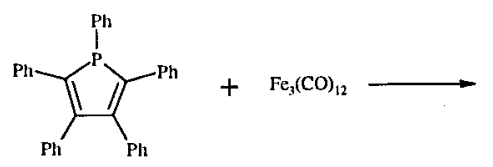

(1)

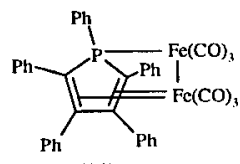

(33)
Figure 21

Later, Mathey and co-workers ${ }^{50,51}$ showed that the main products of the reaction of $\left[\mathrm{Mn}_{2}(\mathrm{CO})_{10}\right]$ with various phospholes were the tridentate complexes $\left[\mathrm{Mn}_{2}(\mathrm{CO})_{7} \mathrm{~L}\right](\mathrm{L}=$ phospholes $)$ analogous to (33). Using 1-phenyl-3,4-dimethylphosphole (19) and $\left[\mathrm{Fe}_{3}(\mathrm{CO})_{12}\right]$ in boiling toluene Mathey and Muller ${ }^{47}$ reported the synthesis of compound (34) (Figure 22) which unlike (33) does not contain an iron-iron bond.

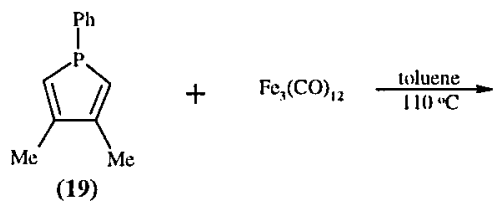

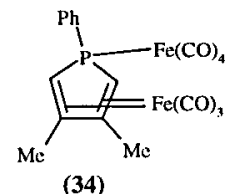

(31)

Figure 22

Figure 19

Several metal fragments have been attached to a phosphole via the phosphorus lone pair. The 1,3,5triphenylphosphole (TPP) (30) for example reacted with 1 equivalent of $\left[\mathrm{M}(\mathrm{CO})_{6}\right](\mathrm{M}=\mathrm{Cr}, \mathrm{Mo}, \mathrm{W})$ in sealed tubes at high temperatures to give the monosubstituted compound $\left[\mathrm{M}(\mathrm{CO})_{5} \mathrm{~L}\right](\mathrm{L}=\mathrm{TPP})(\mathbf{3 1})^{45}$ (Figure 19).

The disubstituted compound $\left[\mathrm{M}(\mathrm{CO})_{4} \mathrm{~L}_{2}\right](\mathrm{M}=\mathrm{Cr}$, Mo; $\mathrm{L}=$ DMPP) was also obtained when 1-phenyl-3,4-dimethylphosphole $(\mathrm{DMPP})$ reacts with $\left[\mathrm{M}(\mathrm{CO})_{4}(\text { piperidine })_{2}\right]$ in dichloromethane ${ }^{46}$. Under relative mild conditions $\left[\mathrm{Fe}_{2}(\mathrm{CO})_{9}\right]$ also reacted with DMPP to afford $\left[\mathrm{Fe}(\mathrm{CO})_{4} \mathrm{~L}\right](\mathrm{L}=\mathrm{DMPP})^{47}$. A series of platinum (II) complexes of the type cis- $\left[\mathrm{PtX}_{2} \mathrm{~L}_{2}\right](\mathrm{X}=\mathrm{Cl}, \mathrm{Br}, \mathrm{I}$; L $=1-\mathrm{R}$ 3,4-dimethylphosphole; $\mathrm{R}=\mathrm{CH}_{3}, n-\mathrm{C}_{4} \mathrm{H}_{9}, t-\mathrm{C}_{4} \mathrm{H}_{9}, \mathrm{C}_{6} \mathrm{H}_{5}$, $\mathrm{CH}_{2} \mathrm{C}_{6} \mathrm{H}_{5}$ ) have been prepared via the reaction of phospholes either with $\mathrm{PtCl}_{2}$ or $\mathrm{K}_{2} \mathrm{PtCl}_{4}$ in ethanol ${ }^{48}$. The tris-phosphole

Mathey and co-workers ${ }^{52}$ also discovered that complexes of type (34) gave sandwich complexes such as (35) when heated at $150{ }^{\circ} \mathrm{C}$ with an excess of the phosphole (Figure 23). Compound (35) which showed a head-to-tail configuration, was fully characterized by X-ray crystal structure analysis. Depending on the starting materials, a number of mixed heterobimetallic sandwich complexes could be obtained.
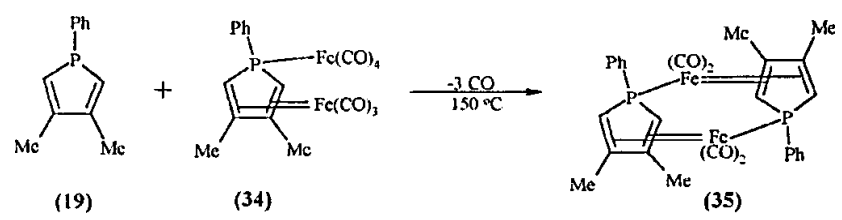

Figure 23 
The coordination chemistry of triphospholes is developing rapidly. As mentioned earlier, the first triphosphole was synthesized only recently. However the results reported so far show the great potential as ligands for this new class of compounds.

Like phospholes, triphospholes can also behave as two, four and six electron donors. The major difference are the two extra phosphorus atoms in the triphosphole rings. Each phosphorus atom has a lonely electron pair, which can be shared with an electrophilic metal center.

Figure 24 shows the reaction of triphosphole (10) with a half equivalent of $\left[\mathrm{PtCl}_{2}\left(\mathrm{PEt}_{3}\right)\right]_{2}$. The product $\eta^{1}$-trans$\left[\mathrm{PtCl}_{2}\left(\mathrm{PEt}_{3}\right)\left(\mathrm{P}_{3} \mathrm{C}_{2} \mathrm{Bu}_{2}^{\mathrm{t}} \mathrm{CH}\left(\mathrm{SiMe}_{3}\right)_{2}\right)\right]$ (36) was the first example of a triphosphole containing a metal complex. In this complex the triphosphole ring behaves as a $2 \mathrm{e}$ donor bonded to the metal via the $s p^{2}$-hybridized phosphorus atom lying between the two carbon atoms.

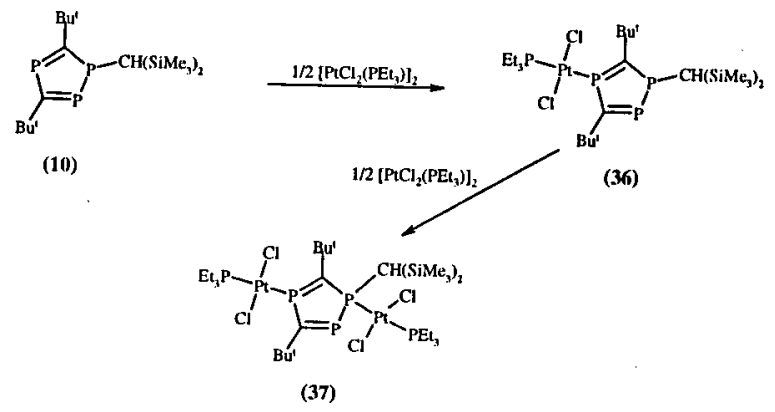

Figure 24

Compound (36) was characterized by several spectroscopic techniques and its molecular structure was determined by an X-ray diffraction study ${ }^{53}$.

Compound (10) can also behave as a $4 \mathrm{e}$ donor. When compound (36) reacts with another half equivalent of $\left[\mathrm{PtCl}_{2}\left(\mathrm{PEt}_{3}\right)\right]_{2}$ the product $\eta^{1}-\eta^{1}$-trans- $\left[\left\{\mathrm{PtCl}_{2}\left(\mathrm{PEt}_{3}\right)\right\}_{2^{-}}\right.$ $\left.\left(\mathrm{P}_{3} \mathrm{C}_{2} \mathrm{Bu}_{2}^{\mathrm{t}} \mathrm{CH}\left(\mathrm{SiMe}_{3}\right)_{2}\right)\right]$ (37) is formed and the second coordination of a Pt-fragment occurs unexpectedly to the only $s p^{3}$-hybridized phosphorus atom (Figure 24), which is the most sterically hindered ${ }^{54}$.

Unlike phospholes, which use the diene system, the triphosphole ligand in compound (37) donates $4 \mathrm{e}$ from the two phosphorus lone pairs. However, triphospholes can also use the diene system to donate $4 \mathrm{e}$ together with another $2 \mathrm{e}$ from the $s p^{3}$-hybridized phosphorus atom, acting as a $6 \mathrm{e}$ donor.

Treatment of compound (10) with $\left[\mathrm{M}(\mathrm{CO})_{4}\left(\eta^{4}-\mathrm{NBD}\right)\right](\mathrm{M}=$ $\mathrm{Cr}, \mathrm{Mo} ; \mathrm{NBD}=$ norbornadiene $)$ in tetrahydrofuran, afforded the red complexes $\left[\mathrm{M}(\mathrm{CO})_{3}\left\{\eta^{5}-\mathrm{P}_{3} \mathrm{C}_{2} \mathrm{Bu}_{2}^{\mathrm{t}} \mathrm{CH}\left(\mathrm{SiMe}_{3}\right)_{2}\right\}\right](\mathrm{M}=\mathrm{Cr}(\mathbf{3 8})$, Mo (39)) in $20 \%$ yield. Likewise reacting (10) with $\left\{\mathrm{W}(\mathrm{CO})_{5}(\mathrm{THF})\right]$ gives $\left[\mathrm{W}(\mathrm{CO})_{3}\left\{\eta^{5}-\mathrm{P}_{3} \mathrm{C}_{2} \mathrm{Bu}_{2}^{\mathrm{t}} \mathrm{CH}\left(\mathrm{SiMe}_{3}\right)_{2}\right\}\right](\mathbf{4 0})$. All three compounds were characterized by several spectroscopic techniques. Compounds (38) and (39) were also fully structurally characterized by a single-crystal X-ray diffraction study ${ }^{55}$. Especially noteworthy is the observation that in both (38) and (39) the tricarbonil fragment is coordinated to all five atoms of the 1,2,4-triphosphole ring system, which is planar. This ring in complexes (38)-(40) can therefore be considered as donating $6 \mathrm{e}$ to the metal center (Figure 25).

The same ligating behavior was found in the zerovalent ruthenium complex $\left[\mathrm{Ru}\left\{\eta^{5}-\mathrm{P}_{3} \mathrm{C}_{2} \mathrm{Bu}_{2}^{\mathrm{t}} \mathrm{CH}\left(\mathrm{SiMe}_{3}\right)_{2}\right\}\left(\eta^{4}-\mathrm{C}_{8} \mathrm{H}_{12}\right)\right]$ (41) obtained from the displacement of naphthalene by the 1,2,4-triphosphole $\mathbf{( 1 0 )}{ }^{56}$.

A different type of ligation for the triphosphole ring system occurs in compound $\left[\mathrm{Fe}_{2}(\mathrm{CO})_{6}\left\{\mu-\mathrm{P}_{3} \mathrm{C}_{2} \mathrm{Bu}_{2}^{\mathrm{t}} \mathrm{CH}\left(\mathrm{SiMe}_{3}\right)_{2}\right\}\right]$ (42) where the ring system acts as a bridging ligand to the two $\mathrm{Fe}(\mathrm{CO})_{3}$ units which are linked together by a $\mathrm{Fe}-\mathrm{Fe}$ bond ${ }^{18}$. The 1,2,4-triphosphole is also considered to act as a $6 \mathrm{e}$ donor,
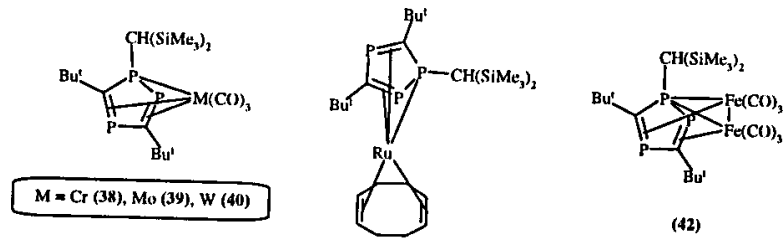

(41)

Figure 25

and its geometry is considerably distorted from that of the parent compound (10).

\section{PHOSPHOLIDE AND POLIPHOSPHOLIDE ANIONS}

Phospholide and polyphospholide anions $\mathrm{P}_{n} \mathrm{C}_{5-\mathrm{n}} \mathrm{R}_{5-\mathrm{n}}(\mathrm{n}=1-5)$ $(\mathrm{R}=\mathrm{H}$, aryl, alkyl) are aromatic five-membered rings resulting from the successive replacements of $\mathrm{CR}$ units of $\mathrm{C}_{5} \mathrm{R}_{5}^{-}$with phosphorus atoms. Figure 26 shows the cyclopentadienyl anion $\mathrm{C}_{5} \mathrm{R}_{5}{ }_{5}(\mathrm{M})$ and all the possible analogous compounds containing phosphorus (N-T).

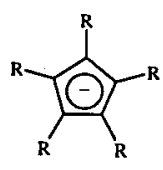

(M)

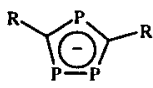

(Q)

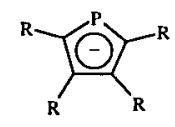

(N)

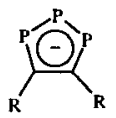

(R)

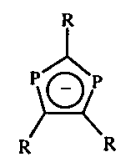

(O)

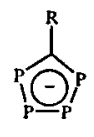

(S)

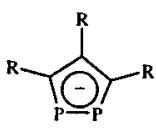

(P)

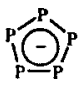

(T)
All of these anions have been isolated, some only very recently, and a recent review covers extensively both the organic and coordination chemistry of some of these interesting species ${ }^{57}$.

\section{SYNTHESIS OF PHOSPHOLIDE AND POLYPHOS- PHOLIDE ANIONS}

The best route to synthesize a phospholide ion involves the cleavage of the P-C exocyclic bond, in an appropriate phosphole system, by an alkali metal ${ }^{37}$. This reaction has already been shown in Figure 12. However, in order to get pure anions without by-product contamination, this synthetic route requires the use of some special phospholes ${ }^{58-61}$, and two examples are given in Figure 27.

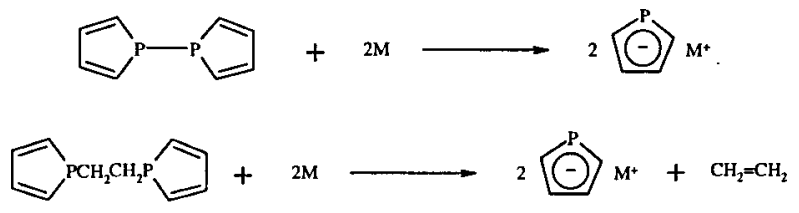

Figure 27

It is interesting to note that other electropositive metals such as samarium and ytterbium can also cleave the P-P bond ${ }^{62}$. Some non-conventional phospholide anions have also been made through alkali metal induced P-P bond cleavage ${ }^{58,63}$, as shown in Figure 28. 


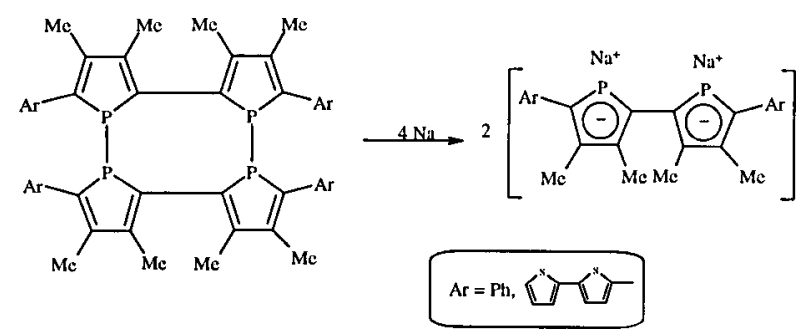

Figure 28

The 1,3-diphospholide anion (7) (see Figure 5) was first detected by Bartsch et al. ${ }^{64}$. It was formed as a by-product in the synthesis of the 1,3,4-triphospholide anion (8) (see Figure 7) by the reaction of $\mathrm{P}-\mathrm{CBu}^{\mathrm{t}}$ with $\mathrm{LiP}\left(\mathrm{SiMe}_{3}\right)_{2}$, which was first described by Becker et al. ${ }^{65}$. Later, Cowley ${ }^{66}$ and Nixon ${ }^{67}$ demonstrated that reduction of the phosphaalkyne, $\mathrm{P}-\mathrm{CBu}^{\mathrm{t}}$, by a sodium amalgam leads to a 1:1 mixture of the di- and triphospholide anions mentioned above (Figure 29).

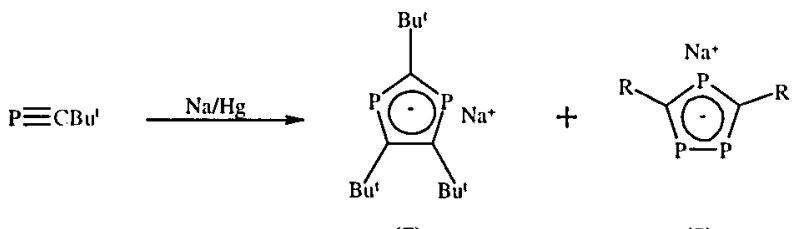

(7)

(8)

Figure 29

Recently, Mathey and co-workers ${ }^{68}$ published the first report describing the synthesis of 1,2-diphospholide anions $(\mathbf{4 3})$. The initial step involved the formation of the 1,2-diphosphacyclopentene (44) by insertion of a phosphinidene into 1,2-dihydrophosphetes (Figure 30). Compound (44) was reduced by lithium in tetrahydrofuran to give the expected compound (43) via a delocalised phosphaallylic anion.

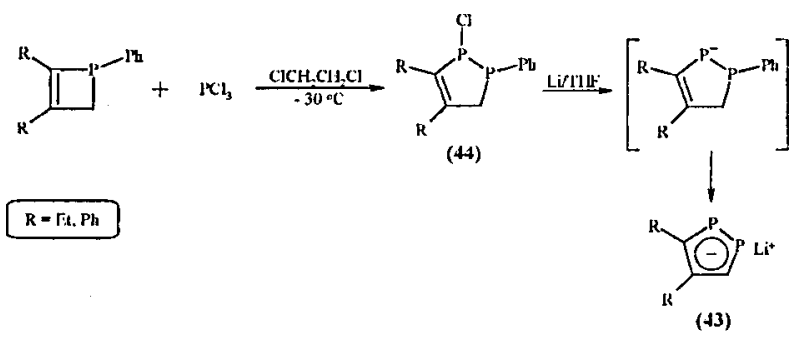

Figure 30

Baudler et al. ${ }^{69,70}$ have reported that 1,2,3-triphospholide (45), 1,2,3,4-tetraphospholide (46) and 1,2,3,4,5-pentaphospholide (47) anions result from treatment of white phosphorus $\left(\mathrm{P}_{4}\right)$ with sodium in dimethoxyethane (Figure 31), where the solvent clearly participates in the reaction mechanism.

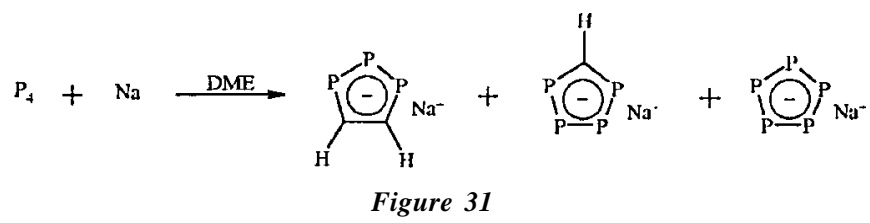

Following the early report no more work has appeared on the tetraphosphorus species, however a specific synthetic route for a 1,2,3-triphospholide anion has been published ${ }^{71}$ as shown in Figure 32. Compound (48), which was synthesized by a specific route, reacted with potassium in dimethoxyethane by breaking the P-P bond. The delocalisation of the negative charge over the P-P-P unit in compound (49) prevents the collapse of the 5-membered ring during the subsequent cleavage of the $\mathrm{P}-\mathrm{Ph}$ bonds to give (50).

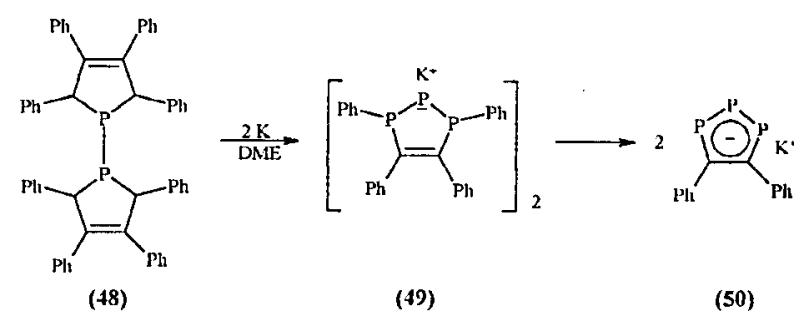

Figure 32

A better synthetic route for the pentaphospholide anion (47) has also been reported ${ }^{72,73}$. Sodium dihydrogenphosphide reacts with white phosphorus, in tetrahydrofuran, in the presence of 18-crown- 6 to give a pure tetrahydrofuran solution of $\mathrm{NaP}_{5}$, because the by-products tend to precipitate from the mixture (Figure 33).

\section{$\mathrm{P}_{4}+\mathrm{NaPH}_{2}$ \\ 18-crown-6

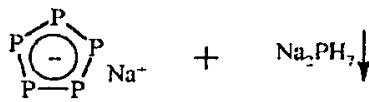 \\ (47) \\ Figure 33 \\ STRUCTURAL DATA AND AROMATICITY OF PHOSPHOLIDE AND POLYPHOSPHOLIDE ANIONS}

Structural data on phospholide and polyphospholide anions are still scarce. The only reported X-ray crystal structure analysis of a phospholide anion was published by Douglas and Theopold in $1989^{74}$. The molecular structure of $\mathrm{Li}(\mathrm{TMEDA}) \mathrm{PC}_{4} \mathrm{Me}_{4}(\mathbf{5 1})$ is shown in Figure 34 and features a planar ring that is $\eta^{5}$ coordinated to lithium. The coordination sphere of the alkali metal is completed by a chelating tetramethylethylenediamine (TMEDA) ligand. The carbon-carbon bond distances within the heterocycle $(\mathrm{C}(1)-\mathrm{C}(2)=1.396, \mathrm{C}(2)-\mathrm{C}(3)=1.424, \mathrm{C}(3)-\mathrm{C}(4)=$ $1.396 \AA)$ are very similar, indicating a high degree of delocalisation. Similarly, the phosphorus-carbon bonds (P-C (1) $=1.750, \mathrm{P}-\mathrm{C}(4)=1.752 \AA)$ are significantly shorter than $\mathrm{P}-\mathrm{C}$ single bonds ( $c a .1 .83 \AA$ ) , consistent with partial double-bond character. These structural features are a direct evidence of the highly aromatic nature of the phospholyl anions.

Delocalisation is also obvious in the tetraphenyltetraphosphafulvalene dianion (52), which is shown in Figure $35^{75}$. The molecular structure of this compound shows that the two rings are strictly coplanar and the $\mathrm{C}-\mathrm{C}$ bridge bond is rather long (1.482(5) $\AA$ ), indicating only a weak conjugative interaction between the two halves of the molecule. All four P-C bonds within each ring are very similar in length, lying between $1.748(3) \AA$ and 1.761(3) $\AA$. The intracyclic C-C bond distance (1.401(4) A) suggests some partial double-bond character. This data support the description of this type of ring system as aromatic.

The only other available data concerning the 1,2,4triphospholide anion (8) is shown in Figure 36. The molecular structure of the lithium salt of the $1,2,4-\left(\mathrm{P}_{3} \mathrm{C}_{2} \mathrm{Bu}_{2}^{\mathrm{t}}\right)^{-}$anion was determined by Becker et al. ${ }^{65}$ and Caliman et al. ${ }^{76}$, however only some partial structural information has been published. 


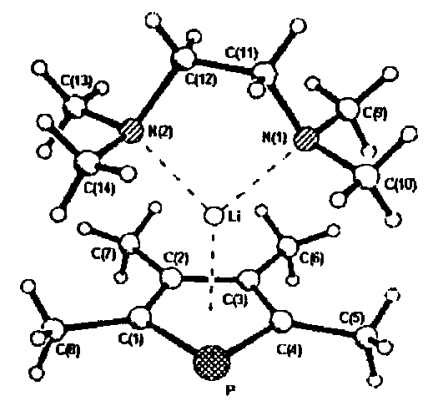

$\mathrm{P}-\mathrm{C}(1)=1.750(5), \mathrm{P}-\mathrm{C}(4)=1.752(4), \mathrm{C}(1)-\mathrm{C}(2)=1.396(5), \mathrm{C}(2)-\mathrm{C}(3)=1.424(7), \mathrm{C}(3)-\mathrm{C}(4)=1.396(7), \mathrm{C}(1)-\mathrm{P}-\mathrm{C}(4)=90.5(2)$, $\mathrm{P}-\mathrm{C}(1)-\mathrm{C}(2)=112.2(4), \mathrm{C}(1)-\mathrm{C}(2)-\mathrm{C}(3)=112.6(4), \mathrm{C}(2)-\mathrm{C}(3)-\mathrm{C}(4)=112.2(4) . \mathrm{C}(3)-\mathrm{C}(4)-\mathrm{P}=112.4(4)$.

Figure 34. Molecular structure of $\mathrm{Li}(\mathrm{TMEDA}) \mathrm{PC}_{4} \mathrm{Me}_{4}$ (51) together with the atomic numbering scheme and selected bond lengths $(A)$ and bond angles $\left({ }^{\circ}\right)^{74}$.

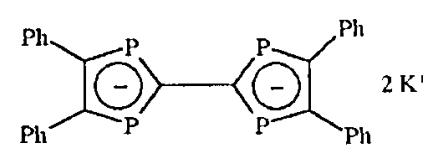

(52)

Figure 35. Tetraphenyltetraphosphafulvalene dianion (52).

The $\mathrm{P}-\mathrm{C}$ bond lengths are very similar to those recorded for the anion $\left(\mathrm{PC}_{4} \mathrm{Me}_{4}\right)^{-}(\mathbf{5 1})$ and the dianion $\left(\mathrm{P}_{2} \mathrm{C}_{3} \mathrm{Ph}_{2}\right)_{2}{ }^{-2}(\mathbf{5 2})$ being $1.75 \AA$, and the P-P bond is substantially shortened with respect to a normal single bond (2.11 $\AA$ versus $2.21 \AA$ ).

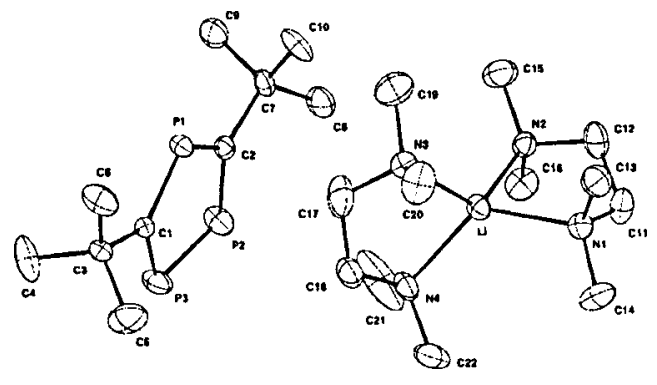

$\mathrm{P}(2)-\mathrm{P}(3)=2.087(2), \mathrm{P}(1)-\mathrm{C}(1)=1.735(5), \mathrm{P}(1)-\mathrm{C}(2)=1.730(5), \mathrm{P}(2)-\mathrm{C}(2)=1.738(4), \mathrm{P}(3)-\mathrm{C}(1)=1.740(5), \mathrm{C}(2)-\mathrm{P}(1)-$ $\mathrm{C}(1)=101.4(2), \mathrm{C}(2)-\mathrm{P}(2)-\mathrm{P}(3)=99.9(2), \mathrm{C}(1)-\mathrm{P}(3)-\mathrm{P}(2)=99.8(2), \mathrm{P}(1)-\mathrm{C}(2)-\mathrm{P}(2)=119.5(3), \mathrm{P}(1)-\mathrm{C}(1)-\mathrm{C}(1)-\mathrm{P}(3)=119.3(3)$.

Figure 36. Molecular structure of $\left[\mathrm{Li}\left(\mathrm{P}_{3} \mathrm{C}_{2} B \mathrm{Bu}_{2}{ }_{2}\right)\right] .2 T M E D A(8)$ together with the atomic numbering scheme and selected bond lengths $(\AA)$ and bond angles $\left({ }^{\circ}\right)$.

These three X-ray crystal structure analyses convincingly establish that phospholide and polyphospholide anions are highly aromatic species. A recent theoretical study by Malar ${ }^{77}$ fully supports this conclusion. The following aromaticity order for this type of ring system has been computed $(100 \%$ of relative aromaticity of $\left.\left(\mathrm{C}_{5} \mathrm{H}_{5}\right)^{-}\right)$: $\left(\mathrm{P}_{5}\right)^{-} 100.6>1,2,4-\left(\mathrm{P}_{3} \mathrm{C}_{2} \mathrm{H}_{2}\right)-$ $95.9>\left(\mathrm{P}_{4} \mathrm{CH}\right)^{-} 94.8>\left(\mathrm{PC}_{4} \mathrm{H}_{4}\right)^{-} 90.7>1,3-\left(\mathrm{P}_{2} \mathrm{C}_{3} \mathrm{H}_{3}\right)^{-} 88.4>$ $1,2-\left(\mathrm{P}_{2} \mathrm{C}_{3} \mathrm{H}_{3}\right)^{-}=1,2,3-\left(\mathrm{P}_{3} \mathrm{C}_{2} \mathrm{H}_{2}\right)^{-} 86.0 \%$.

\section{REACTIVITY OF PHOSPHOLIDE AND POLYPHOSPHOLIDE ANIONS}

All known reactions of phospholide and polyphospholide anions take place at phosphorus atoms. Thus, protonation by acids gives unstable $1 \mathrm{H}$-phospholes and $1 \mathrm{H}$-polyphospholes that instantly give dimers of various structures ${ }^{78-82}$. Two representative cases are exemplified in Figures 37 and 38.

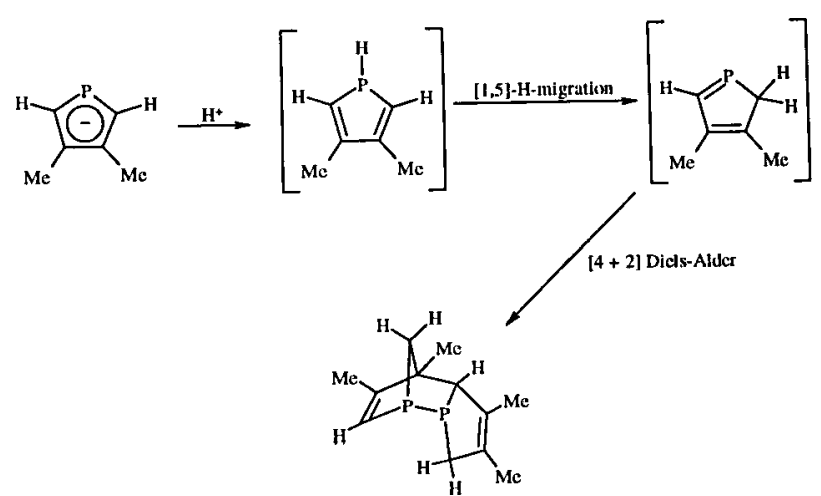

Figure 37. Mechanism involved in the synthesis of $P_{2} C_{8} M e_{4} H_{6}$.
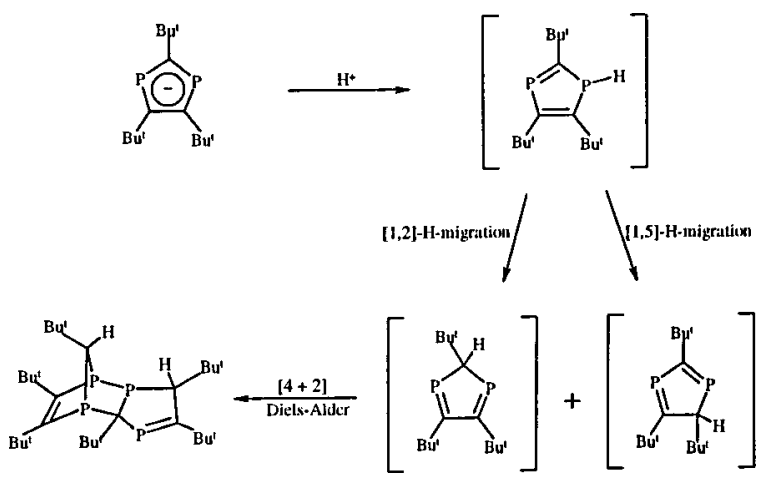

Figure 38. Proposed mechanism for the synthesis of $\mathrm{P}_{4} \mathrm{C}_{6} \mathrm{Bu}_{6}{ }_{6} \mathrm{H}_{2}$.

More generally, all the classical electrophilic species (RX, $\mathrm{O}_{2}, \mathrm{~S}_{8}, \mathrm{X}_{2}$, etc.) preferentially react at phosphorus to give the expected 1R-phosphole ( $\mathrm{R}=$ alkyl, aryl, $\mathrm{S}, \mathrm{O}$, etc.), either as stable or unstable species ${ }^{57}$. The alkylation at phosphorus by alkyl halides is by far the most useful reaction of phospholide anions (Figure 39) 37,60,83.

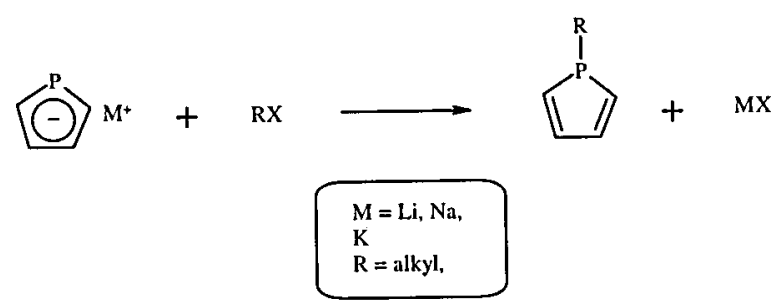

Figure 39

It is noteworthy that alkylation of polyphospholide anions usually gives unstable polyphospholes (see Figure 8) and the only two successful examples of this type of reaction are shown in Figures 4 and 7.

\section{COORDINATION CHEMISTRY OF PHOSPHOLIDE AND POLYPHOSPHOLIDE ANIONS}

The coordination chemistry of cyclopentadienyl rings containing phosphorus is concentrated on four anionic rings, specifically (i) phospholide, (ii) 1,3-diphospholide, (iii) 1,2,4triphospholide and (iv) pentaphospholide anions. The other anion ring systems contribute with only a few examples to the literature and will not be shown here. Many reviews $44,57,84-86$ discuss in detail this type of chemistry where many more examples can be found.

All these anionic ring systems have been $\eta^{5}$-bonded to metal 
centers and due to the phosphorus electron lone pairs available, several other coordination possibilities exist.

Some rare earth metals such as samarium (II) and ytterbium (II) have recently been used to prepare bent metallocenes containing the phospholyl anion. These complexes were obtained either by reaction of the appropriate phospholide anion with the corresponding metal diiodide, or directly by cleavage of the P-P bond of 1,1-biphospholyls with the activated metallic powders (Figure 40) ${ }^{62}$. Single crystal X-ray structure analysis of the 2,5-diphenylphospholylytterbium derivative shows a centroid-Yb-centroid bond angle of $129^{\circ}$ and indicates that the geometry of the $\eta^{5}$-ligated phospholyl rings is similar to that of the free ion.
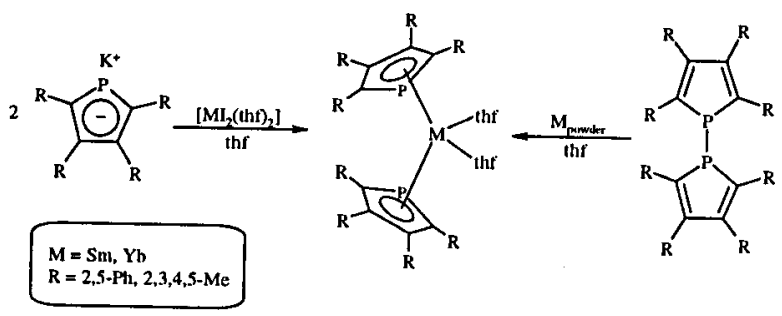

Figure 40

Interestingly, the 1,3-diphospholide ring (7) was the only one that gave a $\eta^{3}$-complex. Nixon and co-workers ${ }^{87}$ showed that $\left[\mathrm{NiBr}_{2}\right]$ reacts with a mixture of di- (7) and triphospholide (8) anions to give the 18 electron nickelocene complex (53) (Figure 41). This was the first example of a complex containing one normal and one "slipped" ring in a simple metal sandwich complex containing no other attendant ligands.

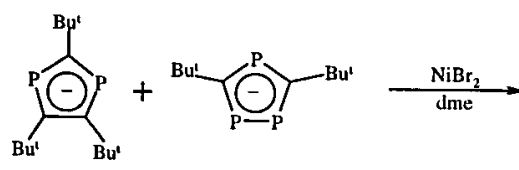

(7)
(8)

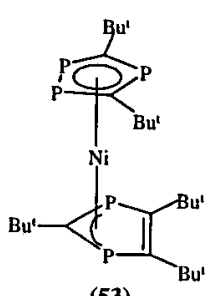

(53)
Figure 41

An attempt to make a 19 electron metallocene by treatment of $\left[\mathrm{CoCl}_{2}\right]$ with the 1,2,4-triphospholide anion $(\mathbf{8})$ led to the synthesis of compound (54) (Figure 42) ${ }^{88}$. The complex may arise from the expected intermediate paramagnetic compound $\left[\mathrm{Co}\left(\eta^{5}-\mathrm{P}_{3} \mathrm{C}_{2} \mathrm{Bu}_{2}\right)_{2}\right]$ by $\mathrm{H}$ abstraction from the ether solvent used in the reaction.

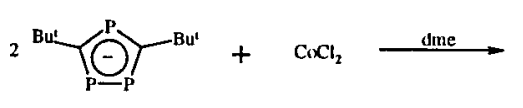

(8)

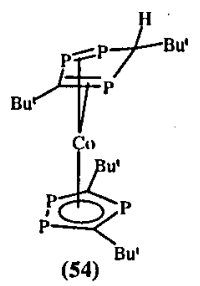

(54)
Figure 42

It is noteworthy that the co-condensation of metal atoms, generated by the metal vapor synthesis (MVS) techniques, with the phosphaalkyne $\mathrm{P}^{3} / 4 \mathrm{CBu}^{\mathrm{t}}$, leads to a variety of novel organometallic sandwich compounds ${ }^{89-93}$. Interestingly, the 1,3- di- (7) and 1,2,4-triphospholide (8) rings are often obtained as ligands in the complexes synthesized by this route (Figure 43).

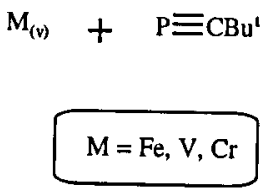

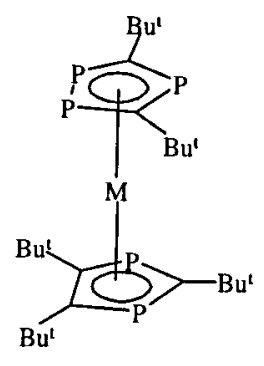

Figure 43
Pioneering work by Scherer and co-workers ${ }^{94}$ has established that the pentaphospholide anion $\left(\mathrm{P}_{5}\right)^{-}$also shows the basic $\eta^{5}$ and $\eta^{5}-\eta^{1}$ - coordination mode and up to four metals have been connected to the phosphorus lone pairs of a central $\left(\mathrm{h}^{5}-\mathrm{P}_{5}\right)$ unit. In addition the $\mathrm{P}_{5}$ ring anion behaves as a bridging ligand between two iron centers in a triple-decker structure (Figure 44).
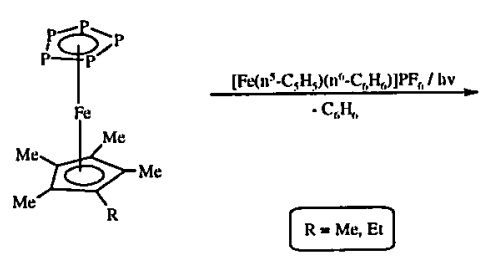

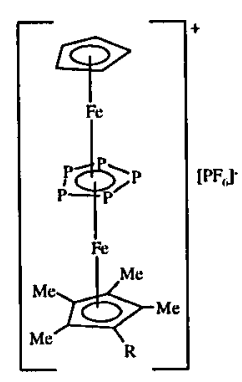

Figure 44
This behavior was specific for the $\left(\mathrm{P}_{5}\right)^{-}$anion until recently when Hitchcock et al. ${ }^{95}$ reported a similar triple-decker structure using the $1,2,4-\mathrm{P}_{3} \mathrm{C}_{2} \mathrm{Bu}_{2}^{\mathrm{t}}$ ring system bridging two ruthenium centers.

\section{ACKNOWLEDGEMENTS}

I thank the Brazilian Government via the CNPq and the UFMG via Pró-Reitoria de Pesquisa-PrPq, for the financial support and Professor John F. Nixon for his suggestion.

\section{REFERENCES}

1. Leavitt, F. C.; Manuel, T. A.; Johnson, F.; J. Am. Chem. Soc. 1959, 81, 3163.

2. Coggon, P.; McPhail, A. T.; J. Chem. Soc., Dalton Trans. 1973, 1888.

3. Quin, L. D.; Bryson, J. G.; J. Am. Chem. Soc. 1967, 89, 5984.

4. Campbell, I. G. M.; Cookson, R. C.; Hocking, M. B.; Hughes, A. N.; J. Chem. Soc. 1965, 2184

5. Fongers, K. S.; Hogeveen, H.; Kingma, R. F.; Tetrahedron Lett. 1983, 24, 1423.

6. Märkl, G.; Potthast, R.; Angew. Chem. Int. Ed. Engl. 1967, $6,86$.

7. Ferao, A. E.; Deschamps, B.; Mathey, F.; Bull. Soc. Chim. Fr. 1993, 130, 695.

8. Mathey, F.; C. R. Seances Acad. Sci., Ser C 1969, 269, 1066.

9. Brèque, A.; Mathey, F.; Savignac, P.; Synthesis 1981, 983.

10. Brèque, A.; Muller, G.; Bonnard, H.; Mathey, F.; Savignac, P.; Eur. Patent. 41447, 1981; Chem. Abstr. 1982, 96, 143076x. 
11. Isaacs, N. S.; El-Din, G. N.; Synthesis 1989, 967.

12. Quin, L. D.; Borleske, S. G., Engel, J. F.; J. Org. Chem. 1973, 38, 1858.

13. Mercier, F.; Holand, S.; Mathey, F.; J. Organomet. Chem. 1986, 316, 271.

14. Mathey, F.; Lampin, J. P.; Thavard, D.; Can. J. Chem. 1976, 54, 2402.

15. Mathey, F.; Chem. Rev. 1988, 88, 429.

16. Sierra, M. L.; Maigrot, N.; Charrier, C.; Ricard, L.; Mathey, F.; Organometallics 1991, 10, 2835.

17. Al-Juaid, S. S.; Hitchcock, P. B.; Matos, R. M.; Nixon, J. F.; J. Chem. Soc. Chem. Commun. 1993, 267.

18. Caliman, V.; Hitchcock, P. B.; Nixon, J. F.; J. Chem. Soc. Chem. Commun. 1995, 1661.

19. Cloke, F. G. N.; Hitchcock, P. B.; Hunnable, P.; Nixon, J. F.; Nyulászi, L.; Niecke, E.; Thelen, V.; Angew. Chem. Int. Ed. Engl. 1998, 37, 1083.

20. Baudler, M.; Akpapoglou, S.; Ouzounis, D.; Wasgestian, F.; Meinigke, B.; Budzikiewicz, H.; Münster, H.; Angew. Chem. Int. Ed. Engl. 1988, 27, 280.

21. Egan, W.; Tang, R.; Zon, G.; Mislow, K.; J. Am. Chem. Soc. 1970, 92, 1442.

22. Egan, W.; Tang, R.; Zon, G.; Mislow, K.; J. Am. Chem. Soc. 1971, 93, 6205.

23. Coggon, P.; Engel, J. F.; McPhail, A. T.; Quin, L. D.; J. Am. Chem. Soc. 1970, 92, 5779.

24. Bartell, L. S.; Bonham, R. A.; J. Chem. Phys. 1957, 27, 1414.

25. Schäfer, W.; Schweig, A.; Märkl, G.; Hauptmann, H.; Mathey, F.; Angew. Chem. Int. Ed. Engl. 1973, 12, 145.

26. Quin, L. D.; Keglevich, G.; Ionkin, A. S.; Kalgutkar, R.; Szalontai, G.; J. Org. Chem. 1996, 61, 7801.

27. Nyulaszi, L.; Keglevich, G.; Quin, L. D.; J. Org. Chem. 1996, 61, 7808.

28. Chesnut, D. B.; Quin, L. D.; J. Am. Chem. Soc. 1994, $116,5779$.

29. Nyulászi, L.; J. Phys. Chem. 1995, 99, 586.

30. Nyulászi, L.; J. Phys. Chem. 1996, 100, 6194.

31. Dransfeld, A.; Nyulászi, L.; Schleyer, P. von R.; Inorg. Chem. 1998, 37, 4413.

32. Nyulászi, L.; Inorg. Chem. 1996, 35, 4690.

33. Glukhotsev, M. N.; Dransfeld, A.; Schleyer, P. von R.; J. Phys. Chem. 1996, 100, 13447.

34. Mathey, F.; Top. Phosphorus Chem. 1980, 10, 1.

35. Quin, L. D.; The Heterocyclic Chemistry of Phosphorus, Wiley Interscience, New York, 1981.

36. Mathey, F.; Phosphorus \& Sulfur 1994, 87, 139.

37. Braye, E. H.; Caplier, I.; Saussez, R.; Tetrahedron 1971, 27, 5523.

38. Mathey, F.; Tetrahedron 1972, 28, 4171.

39. Mathey, F.; Mercier, F.; Tetrahedron Lett. 1981, 22, 319.

40. Caliman, V.; Hitchcock, P. B.; Nixon, J. F.; Sakarya, N.; Bull. Soc. Chim. Belg. 1996, 105, 675.

41. Thelen, V.; Schmidt, D.; Nieger, M.; Niecke, E.; Schoeller, W.; Angew. Chem. Int. Ed. Engl. 1996, 35, 313.

42. Bachrach, S. M.; Caliman, V.; Nixon, J. F.; J. Chem. Soc. Chem. Commun. 1995, 2395.

43. Caliman, V.; Hitchcock, P. B.; Nixon, J. F.; Chem. Commun. 1998, 1537.

44. Mathey, F.; Fischer, J.; Nelson, J. H.; Struct. Bonding (Berlin) 1983, 55, 153.

45. Cookson, R. C.; Fowles, G. W. A.; Jenkins, D. K.; J. Chem. Soc. 1965, 6406.

46. Santini, C. C.; Fischer, J.; Mathey, F.; Mitschler, A.; J. Am. Chem. Soc. 1980, 102, 5809.

47. Mathey, F.; Muller, G.; J. Organomet. Chem. 1977, 136, 241.

48. MacDougall, J. J.; Nelson, J. H.; Mathey, F.; Inorg. Chem. 1982, 21, 2145.

49. Braye, E. H.; Hübel, W.; Caplier, I.; J. Am. Chem. Soc. 1961, 83, 4406.
50. Mathey, F.; J. Organomet. Chem. 1975, 93, 377.

51. Rosalky, J. M.; Metz, B.; Mathey, F.; Weiss, R.; Inorg. Chem. 1977, 16, 3307.

52. Santini, C. C.; Fischer, J.; Mathey, F.; Mitschler, A.; Inorg. Chem. 1981, 20, 2848.

53. Caliman, V.; Hitchcock, P. B.; Nixon, J. F.; Heteroatom Chem. 1998, 9, 1.

54. Caliman, V.; D. Phil. Thesis, University of Sussex at Brighton, England 1996.

55. Caliman, V.; Hitchcock, P. B.; Nixon, J. F.; Nyulaszy, L.; Sakarya, N.; Chem. Commun. 1997, 1305.

56. Hitchcock, P. B.; Nixon, J. F.; Sakarya, N.; Chem. Commun. 1996, 2751.

57. Mathey, F.; Coord. Chem. Rev. 1994, 137, 1.

58. Mathey, F.; Mercier, F.; Nief, F.; Fischer, J.; Mitschler, A.; J. Am. Chem. Soc. 1982, 104, 2077.

59. Charrier, C.; Mathey, F.; Tetrahedron Lett. 1987, 28, 5025.

60. Charrier, C.; Maigrot, N.; Mathey, F.; Organometallics 1987, 6, 586.

61. Charrier, C.; Bonnard, H.; Mathey, F.; J. Org. Chem. 1982, 47, 2376.

62. Nief, F.; Mathey, F.; Synlett 1991, 745.

63. Bevierre, M. O.; Mercier, F.; Ricard, L.; Mathey, F.; Angew. Chem. Int. Ed. Engl. 1990, 29, 655.

64. Bartsch, R.; Hitchcock, P. B.; Nixon, J. F.; J. Chem. Soc. Chem. Commun. 1987, 1146.

65. Becker, G.; Becker, W.; Knebl, R.; Schmidt, H.; Weeber, U.; Westerhausen, M.; Nova Acta Leopold. 1985, 59, 55.

66. Cowley, A. H.; Hall, S. W.; Polyhedron 1989, 8, 849.

67. Bartsch, R.; Nixon, J. F.; Polyhedron 1989, 8, 2407.

68. Maigrot, N.; Avarvari, N.; Charrier, C.; Mathey, F.; Angew. Chem. Int. Ed. Engl. 1995, 34, 590.

69. Baudler, M.; Düster, D.; Ouzounis, D.; Z. Anorg. Allg. Chem. 1987, 544, 87.

70. Baudler, M.; Hahn, J.; Z. Naturforsch. B 1990, 45, 1139.

71. Maigrot, N.; Sierra, M.; Charrier, C.; Mathey, F.; Bull. Soc. Chim. Fr. 1994, 131, 397.

72. Baudler, M.; Etzbach, T.; Chem. Ber. 1991, 124, 1159.

73. Baudler, M.; Ouzounis, D.; Z. Naturforsch. B 1989, 44, 381.

74. Douglas, T.; Theopold, K. H.; Angew. Chem. Int. Ed. Engl. 1989, 28, 1367.

75. Maigrot, N.; Ricard, L.; Charrier, C.; Mathey, F.; Angew. Chem. Int. Ed. Engl. 1992, 31, 1031.

76. Caliman, V.; Hitchcock, P. B.; Jones, C.; Nixon, J. F.; Unpublished results.

77. Malar, E. J. P.; J. Org. Chem. 1992, 57, 3694.

78. Bartsch, R.; Hitchcock, P. B.; Nixon, J. F.; J. Organomet. Chem. 1992, 433, C11.

79. Caliman, V.; Hitchcock, P. B.; Nixon, J. F.; J. Organomet. Chem. 1997, 536, 273.

80. Lauzon, G.; Charrier, C.; Bonnard, H.; Mathey, F.; Fischer, J.; Mitschler, A.; J. Chem. Soc. Chem. Commun. 1982, 1272.

81. Charrier, C.; Bonnard, H.; Lauzon, G.; Mathey, F.; J. Am. Chem. Soc. 1983, 105, 6871.

82. Lauzon, G.; Charrier, C.; Bonnard, H.; Mathey, F.; Tetrahedron Lett. 1982, 23, 511.

83. Deschamps, B.; Mathey, F.; J. Chem. Soc. Chem. Commun. 1985, 1010.

84. Nixon, J. F.; Chem. Ind. (London) 1993, 404.

85. Nixon, J. F.; Chem. Soc. Rev. 1995, 319.

86. Nixon, J. F.; Chem. Rev. 1988, 88, 1327.

87. Bartsch, R.; Hitchcock, P. B.; Nixon, J. F.; J. Organomet. Chem. 1989, 373, C17.

88. Bartsch, R.; Hitchcock, P. B.; Nixon, J. F.; J. Chem. Soc. Chem. Commun. 1988, 819.

89. Arnold, P. L.; Cloke, F. G. N.; Nixon, J. F.; Chem. Commun. 1998, 797. 
90. Arnold, P. L.; Cloke, F. G. N.; Hitchcock, P. B.; Nixon, J. F.; J. Am. Chem. Soc. 1996, 118, 7630.

91. Callaghan, C; Clentsmith, G. K. B.; Cloke, F. G. N.; Hitchcock, P. B.; Nixon, J. F.; Vickers, D. M.; Organometallics 1999, 18, 793.

92. Cloke, F. G. N.; Flower, K. R.; Hitchcock, P. B.; Nixon, J. F.; J. Chem. Soc. Chem. Commun. 1995, 1659.
93. Avent, A. G.; Cloke, F. G. N.; Flower, K. R.; Hitchcock, P. B.; Nixon, J. F.; Vickers, D.; Angew. Chem. Int. Ed. Engl. 1994, 33, 2330.

94. Scherer, O. J.; Brück, T.; Wolmershäuser, G.; Chem. Ber. 1989, 122, 2049.

95. Hitchcock, P. B.; Johnson, J. A.; Nixon, J. F.; Organometallics 1995, 14, 4382. 